\title{
Mathieu repair of distal and midshaft hypospadias: risks and benefits of foreskin reconstruction versus circumcision
}

\author{
Mohammad Kazem \\ Moslemi' \\ Mohammad Ali Sadighi \\ Gilani $^{2}$ \\ Hossein Shahrokh ${ }^{3}$ \\ 'Department of Urology, Kamkar \\ Hospital, School of Medicine, Qom, \\ University of Medical Science, Qom, \\ Iran; ${ }^{2}$ Department of Urology, Shariati \\ Hospital, School of Medicine, \\ Tehran University of Medical Sciences, \\ Tehran, Iran; ${ }^{3}$ Department of Urology, \\ Hasheminejad Kidney Research \\ Center, School of Medicine, Tehran \\ University of Medical Sciences, \\ Tehran, Iran
}

This article was published in the following Dove Press journal:

Open Access Journal of Urology

16 June 2011

Number of times this article has been viewed

Background: The purpose of this study was to compare the risks and benefits of Mathieu repair of hypospadias with or without circumcision in consecutive operated cases.

Methods: Eighty-six children with midshaft or distal hypospadias were randomly divided into two groups and underwent circumcision (Group A) or preputial reconstruction (Group B) during hypospadias repair. Postoperative complications, outcomes, and parental satisfaction were assessed for circumcised and uncircumcised patients. All patients with midshaft or distal hypospadias with or without minimal chordee were included.

Results: No statistically significant differences in urethral complications were found between the two groups. Meatal stenosis occurred in one case in Group A and one case in Group B. Fistulae occurred in five cases in Group A and six cases in Group B. Urethral dehiscence occurred in no case in either group. No case of phimosis was seen in Group B. After a mean follow-up of 6 months, all parents of Group A cases stated that they were satisfied with the circumcision for religious and/or social reasons, but no parents of Group B cases were satisfied with preputioplasty $(P \leq 0.05)$. No case of hypospadias repair failure was seen in our operated cases. Finally, no cases in Group B required redo hypospadias surgery.

Conclusion: Mathieu repair with synchronous circumcision is feasible in all patients with distal or midshaft hypospadias with or without minimal chordee, and should be considered in accordance with surgeon preference. In the case of prepuce preservation, parents should be informed that there is a benefit of tissue banking for probable redo hypospadias repair but with an increased risk of complications and a need for another procedure, ie, circumcision.

Keywords: hypospadias, circumcision, preputioplasty, distal, midshaft, Mathieu repair

\section{Introduction}

A long-standing controversy has surrounded the issue of penile circumcision versus preputioplasty in relation to hypospadias surgery. Most penile surgery for congenital abnormalities includes removal of any foreskin not used in the repair, resulting in circumcision. ${ }^{1}$ Excision of excess foreskin at the time of penile reconstruction is routine in Iran, reflecting a medical, cultural, and religious bias towards circumcision. ${ }^{2,3}$ There are also some trends toward preputioplasty in spite of its complications, such as use of the prepuce as a tissue bank for future repair in the case of failed primary hypospadias repair. The aims of primary hypospadias reconstruction include correction of penile curvature and revising abnormal prepuce by either circumcision or foreskin reconstruction to allow satisfactory voiding and sexual activity. ${ }^{4}$ Our primary objective in this study was to examine whether foreskin reconstruction rather than simple amputation of the foreskin hood influences the short-term urethroplasty complication 
rate for Mathieu repair of midshaft or distal hypospadias. Our secondary objective was to determine the need for prepuce as a tissue material in the case of future hypospadias repair.

\section{Materials and methods}

Eighty-six consecutive patients with midshaft or anterior hypospadias were recruited for this study between March 2004 and March 2009. Their age range was 1-11 years. Mean and median age was 7.9 years and 3 years, respectively. The patients were randomly divided into Group A and Group B, in equal numbers. Group A patients underwent classical Mathieu repair with synchronous circumcision and foreskin repair, and Group B patients underwent delayed metachronous circumcision, with a delay of 6 months. The surgical procedures were performed by a single urologist. Informed consent was taken from the parents in all cases, and consent to perform the study was obtained from our hospital ethics committee. There were no differences between the two groups for demographic data, including age, body weight, type of hypospadias, or social status. Socioeconomic status of the patients was intermediate. SPSS software version 16 (SPSS Inc, Chicago, IL) was used for statistical analysis. The Student's $t$-test was used for evaluation of the statistical significance of findings. Randomization took place in the outpatient clinic before informed consent was taken. The patients were randomized in a simple, alternating $\mathrm{ABAB}$ fashion. We excluded patients who were already circumcised prior to hypospadias repair. It is noteworthy that, before the trial, our standard procedure was to leave behind an unrepaired preputial hood at the time of Mathieu urethroplasty and then remove this secondarily. All parents were told that their child may or may not have a foreskin created as part of the hypospadias repair, and they all consented to this. Our default strategy was that all those in the preputioplasty group would automatically be circumcised 6 months later.

\section{Operative technique}

The Mathieu technique was used in all of our eligible cases with parameatal-based urethroplasty; a neourethral-covering subcutaneous (dartos) pedicle flap developed from the preputial or skin of penile shaft as follows. After general endotracheal or laryngeal mask anesthesia, and in the supine position, a Nelaton 8 French catheter (SUPA, Tehran, Iran) was inserted transurethrally and through the native meatus. The distance between the proposed glans neourethra and the ventral meatus was then measured. Depending on this measurement, the amount of vascularized parameatal cutaneous flap needed was released from the proximal ventral penile skin (Figure 1). Anastomosis of

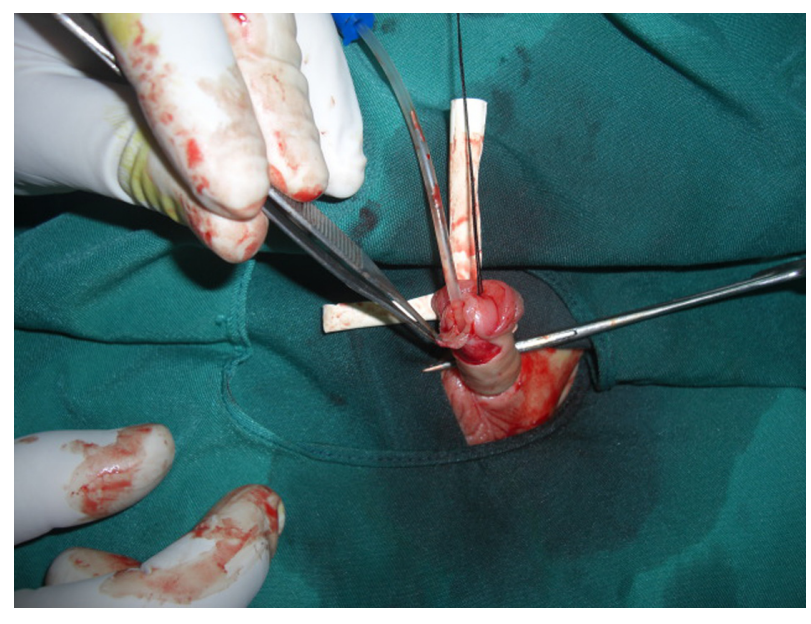

Figure I Adequate parameatal ventral cutaneous flap release.

the released flap with a urethral plate was performed with running 5-0 or 6-0 Vicryl sutures. A second supporting layer was developed from the subcutaneous or preputial penile layers, and neourethral covering was then performed completely (Figures 2 and 3). We avoided using foreskin dartos flaps in patients allocated to preputioplasty (Group B). The incision was performed for circumcision in all cases in Group A, but not for patients in Group B. In Group B, the prepuce was repaired and saved. The dressing was changed after 2 days. The mean duration of hospital stay was 3 days. The urethral catheter was removed after 4-6 days.

\section{Results}

No cases of failed hypospadias repair or redo hypospadias surgery occurred in Group A or in Group B. Five cases $(11.6 \%)$ of urethrocutaneous fistula were seen in Group A and six cases (14\%) in Group B. Follow-up at 3 months, 6 months, and 1 year showed two cases of meatal stenosis

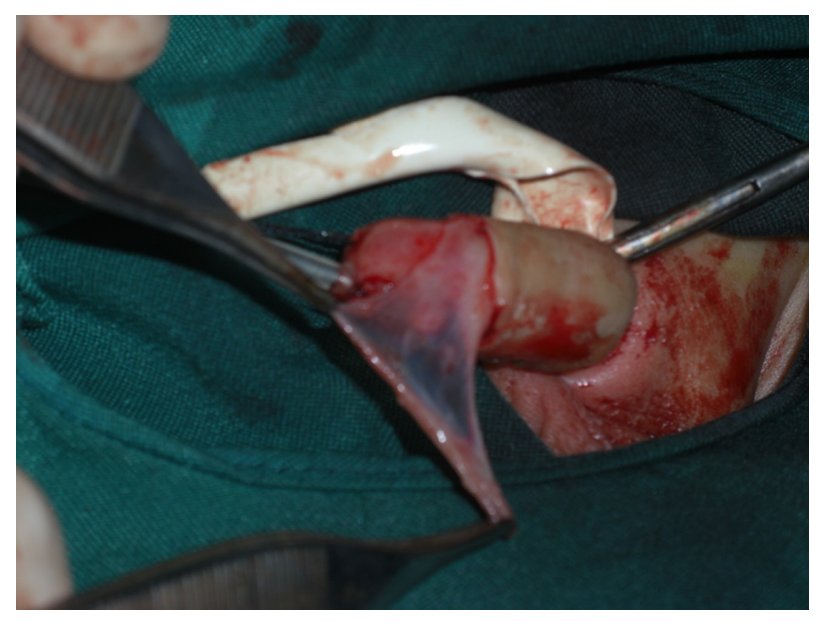

Figure 2 Release of vacularized second layer flap for neourethral coverage. 


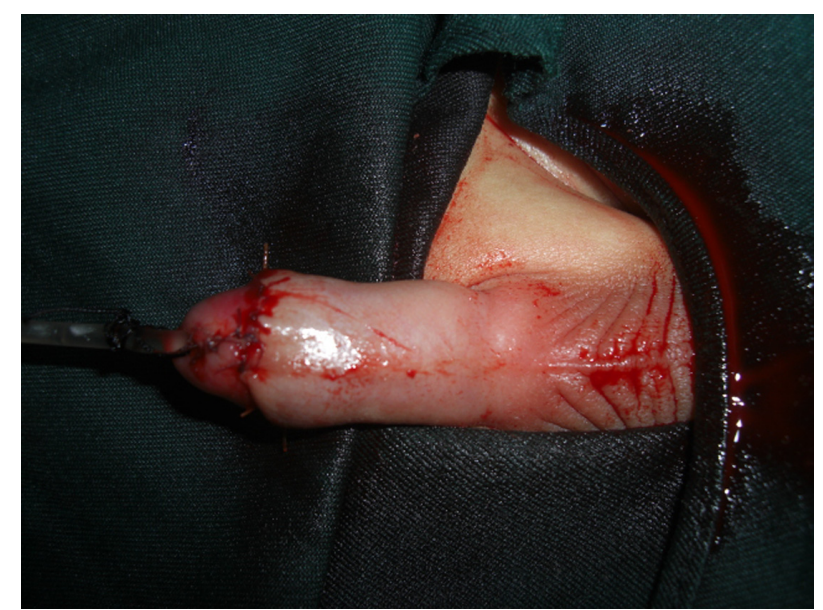

Figure 3 The completed Mathieu repair with synchronous circumcision.

(one case in Group A, one case in Group B). Preputial edema not causing any phimosis was seen in 19 cases (44\%) in Group B, which was transient in all cases and improved spontaneously within 2 weeks. No foreskin reconstructions were deemed to be phimotic, implying that these could be retracted. Preputial necrosis was seen in one case $(2.3 \%)$ in this group of patients (Table 1). Forty patients in Group B underwent the second stage of circumcision 6 months after the primary repair. Circumcision of the three remaining cases was refused by the parents. The cosmetic result was acceptable in all patients from Group A in the opinions of the parents and the physician. For religious/social reasons, all of the parents in Group B were opposed to prepuce preservation before surgery. However, for health reasons, and also the prospective financial burden of second surgery, synchronous circumcision was preferred by 12 (28\%) parents of Group B cases postoperatively. The difference in complications between the two groups was statistically significant $(P \leq 0.05)$. All patients were left with a terminal glans meatus, albeit a stenosed meatus in two cases.

\section{Discussion}

Foreskin reconstruction in distal hypospadias repair has a complication rate of $8.25 \% .^{5}$ This is similar to the $5 \%-8 \%$ complication rate reported in patients undergoing distal hypospadias repair combined with circumcision. ${ }^{6}$ The main benefit of foreskin reconstruction is the availability of foreskin as spare material when a secondary salvage procedure is needed, although the need for major secondary repair in distal hypospadias is negligible. ${ }^{5}$ Circumcision is traditionally performed for three main reasons: religious preference, prophylaxis against some sexually transmitted diseases, and medical considerations. ${ }^{7}$ The most common medical indications are phimosis, penile lymphedema, recurrent paraphimosis, recurrent balanoposthitis, recurrent urinary tract infection, preputial tumors, and after penile degloving procedures to avoid preputial lymphedema. ${ }^{8}$ When the penis is degloved with a circumferential subcoronal incision, doing an elective circumcision as prophylaxis against development of persistent and bothersome preputial lymphedema is common. Preputial lymphedema may be caused by complete discontinuity of distal lymphatic flow after degloving penile incision. ${ }^{8}$ Klijn et al ${ }^{9}$ noted a $33 \%$ complication rate, most commonly fistula formation or partial dehiscence, following hypospadias repair with preputial reconstruction, so discouraged its use. In a study by Snodgrass et $\mathrm{al}^{10}$ comparing the outcomes of tubularized incised plate hypospadias repair and circumcision, no major differences were found for impressions of penile function and appearance after surgery between parents of boys who underwent circumcision versus those who underwent tubularized incised plate hypospadias repair. In another study by Snodgrass et al, ${ }^{1}$ which included 58 patients with hypospadias repair and foreskin preservation; foreskin dehiscence was the most common complication, occurring in 3\% of cases. We observed this in $2.3 \%$ of our cases. Gray et $\mathrm{al}^{11}$ noted complete or partial foreskin dehiscence (the latter referred to as a skin fistula without involvement of the urethra), with an incidence of $0 \%-30 \%$. There were no major complications or reoperations in a study by Aminsharifi et al ${ }^{12}$ of 40 cases in which the combined technique of a Mathieu procedure and a tubularized incised plate with circumcision was used. Snodgrass and $\mathrm{Khavari}^{13}$ reported that prior circumcision in a group of 63 patients with hypospadias and an intact prepuce did not complicate subsequent hypospadias repair in males whose urethral anomaly was concealed by an intact prepuce. ${ }^{13}$ They concluded that circumcision should not be performed in newborns with obvious penile defects, but it could be done in those with a normal prepuce without attention paid to the occasional presence of hypospadias with a normal prepuce. Pieretti et $\mathrm{al}^{14}$ studied the results of 48 repaired and

Table I Type and number of complications in the two groups of Mathieu repair

\begin{tabular}{|c|c|c|c|c|c|c|}
\hline & Meatal stenosis & Urethrocutaneous fistula & Dehiscene & Phimosis & Preputial edema & Preputial necrosis \\
\hline Group A & I case $(2.3 \%)$ & 5 cases $(11.6 \%)$ & 0 & - & - & - \\
\hline Group B & I case $(2.3 \%)$ & 6 cases $(14 \%)$ & 0 & 0 & 19 cases $(44 \%)$ & I case $(2.3 \%)$ \\
\hline
\end{tabular}


previously circumcised patients with glanular, subcoronal, and distal hypospadias. They showed that prior circumcision did not negatively affect their outcomes. Multiple methods for repair of hypospadias have been introduced. However, neourethral dehiscence and urethrocutaneous fistula were the most difficult to treat complications. These problems are common with reoperations, because urethral reconstruction is required in these cases, but only a small amount of penile foreskin is available. ${ }^{15}$ Use of vascularized preputial or penile skin is advised for the repair of complicated hypospadias. In the case of insufficient or unavailable genital skin, it may be necessary to choose extragenital tissues, such as buccal, skin, or bladder mucosa, in order for achieving a successful repair. ${ }^{15,16}$ Mousavi concluded that tubularized incised plate urethroplasty can be used successfully in patients who do not have a healthy skin flap and for circumcised patients when there is a complete lack of foreskin. ${ }^{15}$ Cosmetic results are as important as urinary function. ${ }^{17,18}$ Current therapeutic indications for circumcision with or without hypospadias include trauma, phimosis, paraphimosis, decreased risk of penile or cervical cancer, and a decreased incidence of urinary tract infections, ${ }^{19,20}$ as well as specific complications in the presence of hypospadias. These advantages should be weighed against the complications of circumcision, including bleeding, infection, meatal stenosis, adhesions, amputation of the distal glans, and other more rarely reported problems. ${ }^{19-21}$

\section{Conclusion}

Synchronous hypospadias repair with circumcision is recommended, particularly for distal or midshaft hypospadias repair, as it will not increase the rate of redo hypospadias surgery. The outcome in our patients confirm that hypospadias repair with synchronous circumcision does not complicate hypospadias surgery, especially in the case of failure or fear of it. Based on our study results, circumcision can be performed in the case of distal or midshaft hypospadias without concern for the timing of hypospadias repair or technique, especially when there is a grossly normal prepuce. In the case of preserved foreskin with hypospadias repair, it may have some value as a tissue bank for dealing with occasional urethroplasty complications, especially those occurring as a result of inexperienced hands.

Open Access Journal of Urology

\section{Publish your work in this journal}

The Open Access Journal of Urology is an international, peer-reviewed, open access journal publishing original research, reports, editorials, reviews and commentaries on all aspects of adult and pediatric urology in the clinic and laboratory including the following topics: Pathology, pathophysiology of urological disease; Investigation and treatment of

\section{Disclosure}

The authors report no conflicts of interest in this work.

\section{References}

1. Snodgrass WT, Koyle MA, Baskin LS, et al. Foreskin preservation in penile surgery. J Urol. 2006;176:711-714.

2. Mousavi SA, Salehifar E. Circumcision complications associated with the Plastibell device and conventional dissection surgery: a trial of 586 infants of ages up to 12 months. Adv Urol. 2008;606:123.

3. Kazem MM, Mehdi AA, Golrasteh KZ, et al. Comparative evaluation of two techniques of hemostasis in neonatal circumcision using the Plastibell device. J Pediatr Urol. 2010;6:258-260.

4. Snodgrass WT. Assessing outcomes of hypospadias surgery. $J$ Urol. 2005; 174:816-817.

5. Bhatti AZ, Naveed M, Adeniran A, et al. Preputial reconstruction with distal hypospadias repair. J Pediatr Urol. 2007;3:132-134.

6. Cold CJ, Taylor JR. The prepuce. BJU Int. 1999;83:34-44.

7. Rickwood AM. Medical indications for circumcision. BJU Int. 1999; $83: 45-51$

8. Haseebuddin M, Brandes SB. The prepuce: preservation and reconstruction. Curr Opin Urol. 2008;18:575-582.

9. Klijn AJ, Dik P, de Jong TP. Results of preputial reconstruction in 77 boys with distal hypospadias. J Urol. 2001;165:1255-1257.

10. Snodgrass W, Ziada A, Yucel S, et al. Comparison of outcomes of tubularized incised plate hypospadias repair and circumcision: a questionnaire-based survey of parents and surgeon. $J$ Pediatr Urol. 2008;4:250-254.

11. Gray J, Boston VE. Glanular reconstruction and preputioplasty repair for distal hypospadias: a unique day-case method to avoid urethral stenting and preserve the prepuce. BJU Int. 2003;91:268-268.

12. Aminsharifi A, Taddayun A, Assadolahpoor A, et al. Combined use of Mathieu procedure with plate incision for hypospadias repair: a randomized clinical trial. Urology. 2008;72:305-308.

13. Snodgrass WT, Khavari R. Prior circumcision does not complicate repair of hypospadias with an intact prepuce. J Urol. 2006;176:296-298.

14. Pieretti RV, Pieretti A, Pieretti-Vanmarcke R. Circumcised hypospadias. Pediatr Surg Int. 2009;25:53-55.

15. Mousavi SA. Use of tubularized incised plate urethroplasty for secondary hypospadias repair or repair in circumcised patients. Int Braz J Urol. 2008;34:609-614.

16. Moslemi MK, Firoozabadi MHD. Severe anterior urethral stricture after proximal hypospadias repair - treatment and review of literature. $\mathrm{Am} J$ Case Rep. 2010;11:142-144.

17. Bracka A. A long term view of hypospadias. Br J Plast Surg.1989;42: 251-255.

18. Mureau MAM, Slijper FME, van der Meulen JC, et al. Psychosexual adjustment of men who underwent hypospadias repair: a norm-related study. J Urol. 1995;154:1351-1355.

19. American Academy of Pediatrics. Circumcision policy statement. Pediatrics. 1999;103:686-693.

20. American Urological Association. Circumcision - a continuing controversy. Update Series. 1995;14:170-175.

21. Moslemi MK, Abedinzadeh M, Aghaali M. Evaluation of epidemiology, safety, and complications of male circumcision using conventional dissection surgery: experience at one center. Open Access Journal of Urology. 2011;3:83-87.

\section{Dovepress}

urological disease; Pharmacology of drugs used for the treatment of urological disease. The manuscript management system is completely online and includes a very quick and fair peer-review system, which is all easy to use. Visit http://www.dovepress.com/testimonials.php to read real quotes from published authors. 